\title{
MAPEAMENTO DOS AQUÍFEROS DO ESTADO DA BAHIA UTILIZANDO O ÍNDICE DE QUALIDADE NATURAL DAS ÁGUAS SUBTERRÂNEAS - IQNAS
}

\author{
Iara Brandão de Oliveira ${ }^{1}$, Francisco Inácio Negrão ${ }^{1}$, Alessandra Gomes Lopes Sampaio Silva ${ }^{1}$
}

\begin{abstract}
RESUMO Este trabalho apresenta os mapas de qualidade das águas subterrâneas do Estado da Bahia, utilizando os valores do IQNAS - Índice de Qualidade Natural das Águas Subterrâneas. O IQNAS foi construído à semelhança do Índice de Qualidade das Águas IQA-CETESB que classifica a qualidade das águas superficiais. O cálculo do IQNAS envolve pesos e notas, extraídas de gráficos da concentração do parâmetro hidroquímico, versus a qualidade da água, ou nota, definido pelos autores, com critério semelhante ao estabelecido para o índice IQA-CETESB, ou seja: de 80-100, ótima; de 52-79, boa; de 37-51, aceitável; e de 0-36, imprópria. Os parâmetros utilizados para o cálculo do IQNAS foram: cloreto, $\mathrm{pH}$, sólidos totais, dureza, nitrato e flúor. Foram utilizados os dados consistidos das análises químicas de 1.899 poços cadastrados no Banco de Dados da CERB - Companhia de Engenharia Rural da Bahia, e de 05 amostras de águas minerais, tomadas como padrão, da Bacia Sedimentar do Recôncavo-Tucano. Os dados de IQNAS foram utilizados para construir os mapas de qualidade das águas dos seguintes domínios aqüíferos: Coberturas Detríticas; Bacias Sedimentares; Metassedimentar, Cárstico e Embasamento Cristalino. Verificou-se que os mapas semafóricos de IQNAS, representaram adequadamente a qualidade química natural das águas subterrâneas das regiões estudadas, confirmando positivamente a metodologia adotada.
\end{abstract}

Palavras-chave: Água Subterrânea, Hidroquímica, Índices de Qualidade, IQNAS

\begin{abstract}
This work presents maps of the State of Bahia groundwater quality, built with values of GNQI Groundwater Natural Quality Index. The GNQI was developed similarly to the Water Quality Index - WQI (IQA-CETESB), to classify the surface water quality. The calculation of GNQI values were based on weights and graphs for the concentration of the hydrochemical parameter versus water quality, or grade, defined by the authors of this work, with the same criteria utilized for the IQA-CETESB, which are: 80-100, exceptional quality; 52-79, good; 37-51, acceptable; and 036, improper. The parameters utilized for GNQI calculations were: $\mathrm{pH}$, chloride, total solids, hardness, nitrate and fluorite, obtained from chemical analysis of 1,899 wells, from CERB Data Bank, State of Bahia, Brazil, plus 05 samples of mineral water from the Sedimentary Basin Recôncavo-Tucano, taken as water quality standard. The GNQI data were used to construct the maps of the following aquifer domains: Sedimentary, Metasedimentary, Karst and Crystalline. It was verified that the maps with GNQI values adequately represented the groundwater quality of the studied regions, attesting the usefulness of the adopted methodology.
\end{abstract}

Keywords: groundwater quality index, Bahia, Recôncavo-Tucano sedimentary basin

\section{INTRODUÇÃO}

Tradicionalmente se faz a classificação da qualidade química das águas subterrâneas através de diagramas, os quais descrevem a concentração relativa dos íons principais, $\left(\mathrm{Ca}^{2}, \mathrm{Mg}^{2}, \mathrm{Na}, \mathrm{K}\right.$, $\left.\mathrm{CO}_{3}, \mathrm{HCO}_{3}, \mathrm{SO}_{4}^{2}, \mathrm{Cl}\right)$ e secundários $\left(\mathrm{Fe}^{2}, \mathrm{NO}_{3}\right)$. Tais diagramas servem para indicar a qualidade da água e identificar os processos envolvidos na sua evolução hidroquímica no meio aqüífero.

Dentre os vários diagramas de qualidade da água subterrânea propostos na literatura, destacam-se os colunares, triangulares e lineares. Os mais utilizados são os de Collins (1923), Piper (1944), Stiff (1951) e de Schoeller (1955), apresentados na figura 1.

Os diagramas são representações pontuais de cada amostra, ou de um conjunto de amostras, e, embora possam ser inseridos em mapas temáticos, não são facilmente assimilados pelo público em geral.

O mapeamento da qualidade das águas subterrâneas, através da utilização de índices, representa uma excelente possibilidade de sintetizar tais informações. Em geral, um índice de qualidade de água é um número adimensional obtido da agregação de dados físicos, químicos e bacteriológicos por meio de metodologias específicas. O interesse do Brasil por tais índices vem crescendo, desde que o Conselho Nacional de Meio Ambiente, em seu relatório anual de 1982, sugeriu a utilização destes, para ajudar na gestão dos recursos naturais (PNMA, 2006).

\footnotetext{
1, Departamento de Engenharia Ambiental,UFBA (oliveira@ufba.br;( fnegrao@ufba.br); (aglss@hotmail.com)
} 


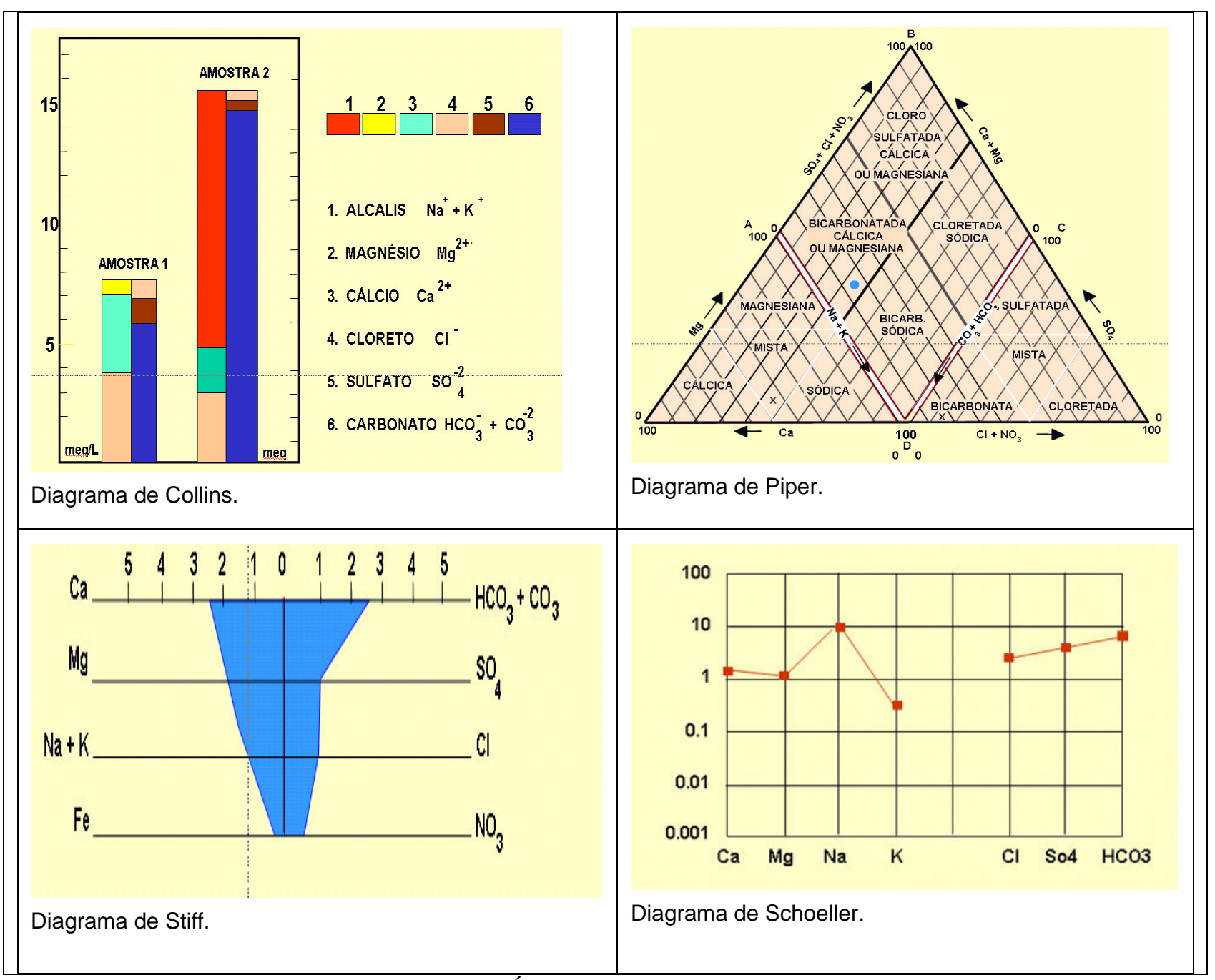

Figura 1 - Principais Diagramas de Qualidade da Água Subterrânea.

Este trabalho apresenta os mapas de qualidade das águas subterrâneas do Estado da Bahia, construídos com o auxílio do programa Arcview, utilizando, na espacialização, os valores obtidos com o cálculo do IQNAS - Índice de Qualidade Natural das Águas Subterrâneas, metodologia desenvolvida por Oliveira et al. (2004a, 2004b, 2005 e 2006) e Silva et al. (2005).

\section{CARACTERIZAÇÃO DA ÁREA DOMÍNIOS HIDROGEOLÓGICOS DO ESTADO DA BAHIA}

O Estado da Bahia, com área territorial de $566.237 \mathrm{~km}^{2}$ (BAHIA, 2003), é constituído dos seguintes domínios hidrogeológicos: Coberturas Detríticas, Bacias Sedimentares, Metassedimentos, Calcários e Embasamento Cristalino, mostrados na figura 2. Está submetido a condições climáticas variáveis, desde precipitações médias anuais de 400 a 2.600 $\mathrm{mm} / \mathrm{ano}$. Nesse contexto, tem-se um potencial de recursos hídricos subterrâneos com uma distribuição geográfica bastante heterogênea. Utilizando-se o fator geologia, associado ao fator climático (precipitação), pode-se delimitar áreas de comportamento hidrogeológico semelhante, compondo-se um mapa com domínios distintos associados aos tipos litológicos e índices pluviométricos. Portanto, cada domínio caracteriza-se pela capacidade de produção de seus poços e pela qualidade natural de suas águas. (GUERRA; NEGRÃO, 1996).

\section{Domínio das coberturas detríticas}

As Coberturas Detríticas dividem-se em coberturas profundas e rasas, distribuídas por várias regiões, cobrindo aproximadamente 15\% da área do Estado $\left(88.273 \mathrm{~km}^{2}\right)$. Dentre as Coberturas Profundas, tem-se a Formação Vazante, depositada nas margens do rio São Francisco, formada por uma espessa camada detrítica que armazena considerável quantidade de águas subterrâneas. 


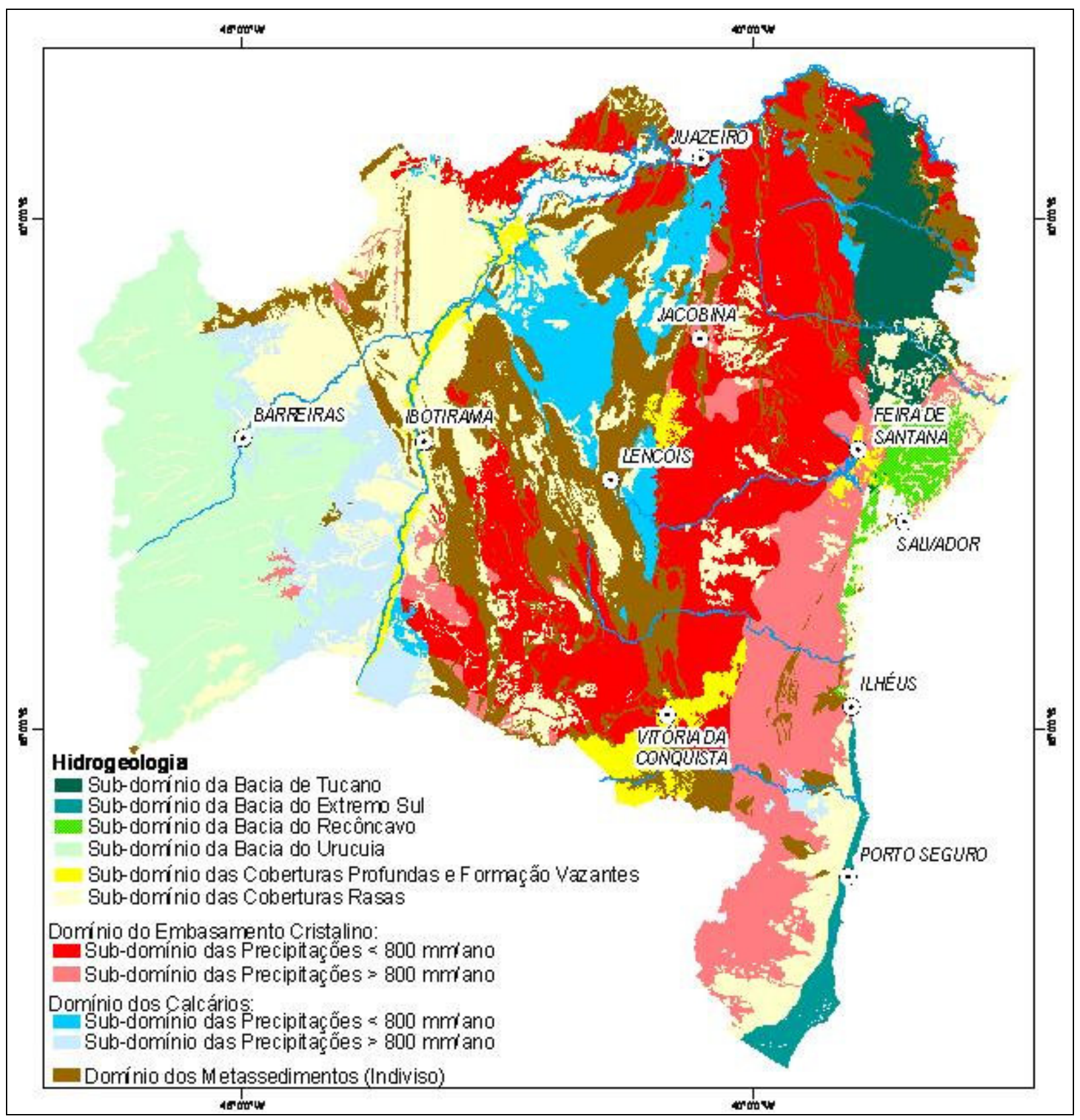

Figura 2 - Domínios Hidrogeológicos do Estado da Bahia.

Os poços tubulares das Coberturas Profundas podem atingir profundidades superiores a $50 \mathrm{~m}$, com vazões de até $90 \mathrm{~m}^{3} / \mathrm{h}$ e águas, em geral, de boa qualidade química.

As Coberturas Rasas recobrem uma extensa área do Estado, com depósitos detríticos do quaternário, constituídos por areias de dunas e aluviões; e depósitos terciários da Formação Barreiras. Esses depósitos, quando espessos, podem armazenar grande volume de água, sendo recarregados diretamente por águas pluviais ou indiretamente pela descarga dos riachos. Para depósitos de pequenas espessuras $(<10 \mathrm{~m})$, os sistemas de captação se dão através de: poços rasos, poços ponteiras, poços com drenos radiais, trincheiras filtrantes e barragens subterrâneas.

\section{Domínio das bacias sedimentares}

O Domínio das Bacias Sedimentares, representado pelas Bacias do Recôncavo/Tucano, Almada, Extremo Sul e Urucuia, abrange aproximadamente $20 \%$ da área do Estado $\left(111.600 \mathrm{~km}^{2}\right)$. Estas bacias, com exceção de parte da Bacia de Tucano, situam-se, predominantemente, em faixas de isoietas acima de 800 mm/ano. As bacias do Recôncavo/Tucano formam um conjunto aqüífero que se estende, desde a Região Metropolitana de Salvador, até a divisa da Bahia com o estado de Pernambuco.

Dentre as bacias, a do Recôncavo é a mais explotada, com poços de até $420 \mathrm{~m}$ de profundidade e produção superior a $400 \mathrm{~m}^{3} / \mathrm{h}$. Esse sistema aqǘf́ero possui a maior 
potencialidade, com ocorrência de água doce a profundidades superiores a $1.000 \mathrm{~m}$ (GUERRA e NEGRÃO, 1996).

\section{Domínio dos metassedimentos.}

Aproximadamente $15 \%$ da área do Estado $\left(84.300 \mathrm{~km}^{2}\right)$ são coberta por metassedimentos, com maior percentual em áreas de precipitações inferiores a $800 \mathrm{~mm} /$ anuais. Os metassedimentos formam aquíferos livres de natureza fissural, similarmente aos aquíferos cristalinos. Diferenciam-se destes, entretanto, por vazões mais elevadas e por menor salinização de suas águas, em parte, devido à sua composição litológica rica em quartzo e, por ocorrerem em regiões de topografia e pluviosidade elevadas, como, por exemplo, a Chapada Diamantina.

\section{Domínio dos calcários}

Os calcários cobrem aproximadamente $14 \%$ da área do Estado $\left(77.900 \mathrm{~km}^{2}\right)$, apresentando porosidade e permeabilidade secundária, de natureza cárstico/fissural. No Estado predominam as rochas carbonatadas do Grupo Bambuí que ocorrem nos limites da bacia do rio São Francisco, nas regiões da Chapada de Irecê, vale do rio Salitre, Vale do Iuiú e região de Santa Maria da Vitória no Oeste do São Francisco. Os calcários propiciam a ocorrência de aqüíferos com um sistema de elevada heterogeneidade e anisotropia, por serem rochas solúveis, apresentando feições morfo/estruturais típicas: dolinas, sumidouros, estruturas de desabamentos, canais de dissolução e cavernas.

A análise dos dados neste domínio mostra uma grande amplitude de variação em termos de vazão e sólidos totais. A média das vazões foi estimada em $9,12 \mathrm{~m}^{3} / \mathrm{h}$, com baixa concentração de cloretos (GUERRA 1986; NEGRÃO, 1987).

\section{Domínio do embasamento cristalino}

As rochas do Embasamento Cristalino cobrem aproximadamente $36 \%$ da área do Estado $\left(201.600 \mathrm{~km}^{2}\right)$, sendo composta essencialmente por granitos, gnaisses, migmatitos e granulitos. Esse domínio é constituído por aqüíferos de natureza fissural, de reduzida potencialidade hídrica, subdividido em função da pluviosidade em dois subgrupos: subdomínio de pluviometria < $800 \mathrm{~mm} / \mathrm{ano}$; e subdomínio de pluviometria > $800 \mathrm{~mm} / \mathrm{ano}$.

No subdomínio $<800 \mathrm{~mm} /$ ano localizam-se as áreas de maior carência hídrica do Estado e maior aridez, decorrentes da baixa capacidade de armazenamento das rochas e do elevado índice de evaporação. Como resultado, tem-se, além da baixa produção dos poços, maior índice de salinidade das águas. O subdomínio > 800 $\mathrm{mm} /$ ano representa o embasamento cristalino das regiões úmidas. Em consequiência da maior pluviosidade, tem-se um manto de intemperismo mais espesso, uma sensível melhoria nas condições de recarga, influenciando na produção dos poços e qualidade química de suas águas. (GUERRA e NEGRÃO, 1996).

\section{MATERIAIS E MÉTODOS}

\section{Desenvolvimento de índices de qualidade das águas.}

Os índices de qualidade das águas servem para facilitar a interpretação de extensas listas de variáveis ou indicadores, resumindo as variáveis envolvidas em um único número, possibilitando a visualização da variação da qualidade da água no tempo e no espaço de forma simples e prática (GASTALDINI e SOUZA, 1994). Entretanto, são poucas as referências encontradas no que se refere aos indicadores de qualidade das águas subterrâneas.

Segundo Fournier (2001), o sistema francês, SEQ - Eaux Souterraines (Système d'Évaluation de la Qualité des Eaux Souterraines), de avaliação das águas subterrâneas, propõe um índice baseado em duas noções: alteração da qualidade e uso do recurso. O SEQ - Eaux Souterraines foi desenvolvido pela Agência de Água, em parceria com o Ministério do Desenvolvimento Regional e Meio Ambiente da França, para avaliar a qualidade da água subterrânea para os diversos usos.

Avaliando o desenvolvimento do $S E Q$ - Eaux Souterraines, Fournier (2001) considera que uma das dificuldades é qualificar as águas subterrâneas, pois, para esse autor, não existe uma qualidade "a priori", mas qualidades que podem satisfazer um ou outro uso. A ferramenta $S E Q$ - Eaux Souterraines adota vários critérios de qualidade da água, definida em relação aos usos, tais como: água potável, para indústrias agroalimentícias, outras indústrias, produção de energia, irrigação e dessedentação de animais. $\mathrm{O}$ Índice Geral de Qualidade $S E Q$ - Eaux Souterraines reagrupa os parâmetros por alterações de qualidade, por exemplo: nitratos, pesticidas, hidrocarbonetos; e considera o índice variando entre zero e 100 , sendo o valor zero (água de pior qualidade) e o valor 100 (água da melhor qualidade).

A formulação matemática do SEQ - Eaux Souterraines, em muito se assemelha ao método de construção do referencial WQI - Water Quality 
Index proposto pela NSF (National Sanitation Foundation), construído para exprimir a qualidade das águas superficiais em diversos ambientes: rios, lagos, água estuarina e água distribuída (NSF, 2004). O WQI foi adaptado, em 1970, pela Companhia de Tecnologia de Saneamento Ambiental - CETESB, para uso no Brasil, renomeado de IQA - Índice de Qualidade de Água, (PORTO, 1991). O IQA varia entre zero e 100 , e, quanto maior for o valor do IQA, melhor será a qualidade da água.

Construção do índice de qualidade natural das águas subterrâneas - IQNAS

A metodologia utilizada para desenvolver o Índice de Qualidade Natural das Águas Subterrâneas - IQNAS envolveu os seguintes estágios: levantamento da opinião de especialistas; utilização de dados hidroquímicos; e aplicação de métodos estatísticos, seguindo um roteiro similar ao discutido em Leite e Fonseca (1994).

O IQNAS foi concebido preenchendo os critérios gerais normalmente adotados para a construção de índices de qualidade, ou seja: (1) o número de variáveis incorporadas ao índice é limitado, a fim de garantir a praticidade; (2) as variáveis utilizadas são parâmetros químicos mais significativos para se avaliar a qualidade natural das águas subterrâneas em estudo; (3) as variáveis escolhidas são aquelas, dentro da disponibilidade de dados, ou seja, são as análises químicas das águas subterrâneas mais freqüentemente realizadas.

O procedimento utilizado na elaboração do índice compreendeu as seguintes etapas: a escolha do modelo matemático; a escolha dos parâmetros químicos; a construção da curva da nota de qualidade versus concentração ou magnitude do parâmetro; e determinação dos pesos.

\section{Escolha do modelo matemático}

A formulação matemática escolhida para o IQNAS foi a mesma utilizada para o IQA da CETESB, ou seja, um produto dos valores de qualidade da água subterrânea para cada parâmetro químico escolhido $\left(\mathrm{Q}_{\mathrm{i}}\right)$, elevado ao peso atribuído a cada variável $\left(\mathrm{w}_{\mathrm{i}}\right)$. Onde:

$$
\begin{aligned}
& \text { IQNAS }= \\
& \text { Produto }\left(\mathrm{Q}_{\mathrm{i}}{ }^{\mathrm{wi}}\right)=\mathrm{Q}_{1}{ }^{\mathrm{w} 1} \times \mathrm{Q}_{2}{ }^{\mathrm{w} 2} \times \mathrm{Q}_{3}{ }^{\mathrm{w} 3} \mathrm{x} \ldots . . \mathrm{Q}_{\mathrm{n}}{ }^{\mathrm{wn}} ;
\end{aligned}
$$

Para determinar-se a qualidade da água subterrânea para cada parâmetro químico escolhido (Qi), foi necessário estabelecer seis relações matemáticas entre a concentração de cada parâmetro escolhido (por exemplo, o teor de cloreto na água) e a qualidade da água, representada por uma nota que varia de 0 a 100. Utilizou-se como base, a escala de notas definida para o cálculo do IQA, constante em Porto (1991). Nesta escala, os intervalos de notas e a qualidade atribuída a cada um deles são: nota de 80 a 100 (qualidade ótima), de 52 a 79 (boa), de 37 a 51 (aceitável), de 20 a 36 (imprópria para tratamento convencional) e de 0 a 19 (imprópria). Tendo em vista que a água subterrânea, em geral, não é submetida a tratamento convencional, a escala escolhida para o IQNAS foi a seguinte: nota de 80 a 100 (qualidade ótima), de 52 a 79 (boa), de 37 a 51 (aceitável), de 0 a 36 (imprópria).

\section{Escolha dos parâmetros químicos}

Os parâmetros químicos escolhidos para avaliar a qualidade natural das águas subterrâneas nos vários domínios hidrogeológicos do estado da Bahia (calcário, cristalino, metassedimentar e sedimentar), foram aqueles associados às variações mais significativas da qualidade da água nos domínios hidrogeológicos do Estado. Assim sendo, cloreto e sólidos totais foram escolhidos por representar a alta salinidade dos aquíferos cristalinos. A dureza, por ser o parâmetro caracterizador da qualidade da água nos domínios calcários. O fluoreto, por existir regiões do cristalino e calcário, com altos teores deste íon, inclusive com impacto na saúde da população. $\mathrm{O}$ nitrato, por ser um indicador da alteração da qualidade da água subterrânea; e o $\mathrm{pH}$, como indicador de acidez e alcalinidade das águas.

\section{Construção das curvas de qualidade versus concentração}

Para construir cada gráfico de "qualidade $\mathrm{x}$ concentração ou magnitude do parâmetro físicoquímico", foi necessário determinar-se os pontos iniciais associados às qualidades ótima, aceitável e imprópria.

Para os parâmetros cloreto, dureza e nitrato, o padrão de controle da qualidade ótima foram amostras de água mineral do aquífero São Sebastião, da Bacia Sedimentar do Recôncavo, envasadas por três engarrafadoras da região (Fresca, Indaiá e Schincariol). Assim sendo, os teores dos elementos químicos: cloreto, dureza e nitrato, presentes nessas águas, foram tomados como representantes da qualidade ótima (nota 100). Para determinar a qualidade da água 
subterrânea entre ótima e aceitável, nos gráficos de cloreto, dureza e nitrato, tomou-se como o final do intervalo da qualidade aceitável (nota 37), o valor máximo aceitável de cada parâmetro, conforme recomendado na Portaria 518/2004 do Ministério da Saúde.

Para o fluoreto, por sua dupla característica, ou seja, necessário à boa formação óssea, quando em baixos teores, mas danoso à saúde humana para teores elevados utilizou-se o seguinte critério: foi atribuída nota (80) ao teor zero; e notas, (100) ao teor mínimo $\left(1,0 \mathrm{mgL}^{-1}\right)$ e nota (zero) ao teor máximo $\left(1,5 \mathrm{mgL}^{-1}\right)$, teores estes

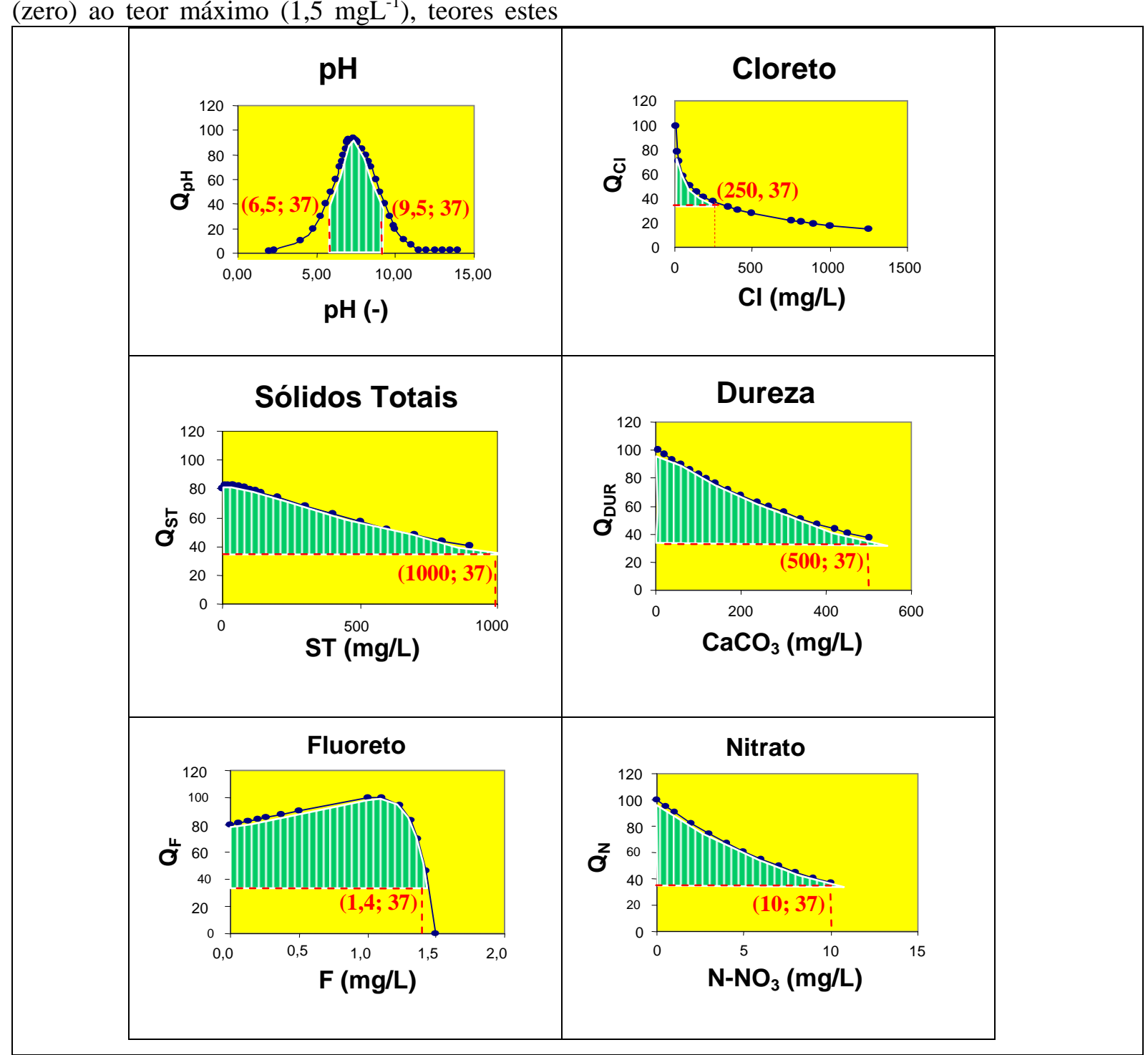

Figura 3 - Curvas de Qualidade versus Concentração do Parâmetro Físico-Químico. recomendado pela Portaria 518/2004 do Ministério da Saúde.

Para o parâmetro resíduo total, a nota (80) foi associada ao teor zero, seguindo a mesma proposta do IQA CETESB; enquanto a nota (37) foi associada ao teor máximo, (500 $\left.\mathrm{mgL}^{-1}\right)$, recomendado pela Portaria 518/2004.

Para o $\mathrm{pH}$, o gráfico foi tomado integralmente do modelo utilizado para o IQA CETESB. Os gráficos de qualidade versus concentração estão mostrados na figura 3 . 
Tabela 1: Equações matemáticas para as curvas de qualidade versus concentração

\begin{tabular}{|c|c|c|c|c|}
\hline $\begin{array}{l}\text { Parâmetros e } \\
\text { Unidades }\end{array}$ & Equações Matemáticas & $\begin{array}{l}\text { Intervalos } \\
\text { de Validade }\end{array}$ & $\mathbf{R}^{2}$ & $\begin{array}{l}\text { Pesos } \\
\left(w_{i}\right)\end{array}$ \\
\hline $\begin{array}{l}\mathrm{pH}, \\
(-)\end{array}$ & $\begin{array}{c}Q_{p H}=1,7354 \times(p H)^{2} \\
Q_{p H}=16405 \times\left[(p H)^{-2,5}\right]-17\end{array}$ & $\begin{array}{c}{[2 \leq \mathrm{pH} \leq 7,34]} \\
{[\mathrm{pH} \geq 7,35]}\end{array}$ & 0,990 & 0,05 \\
\hline $\begin{array}{l}\text { Cloreto, } \\
\left(\mathrm{Cl}, \mathrm{mg} \mathrm{L}^{-1}\right)\end{array}$ & $\begin{array}{c}Q_{\mathrm{Cl}}=100 \\
Q_{\mathrm{Cl}}=138,9 \times(\mathrm{Cl})^{-0,19561}-(\mathrm{Cl})^{0,42} \\
Q_{\mathrm{Cl}}=0,0\end{array}$ & $\begin{array}{c}{[\mathrm{Cl}<4,86]} \\
{[4,86 \leq \mathrm{Cl} \leq 3000]} \\
{[\mathrm{Cl}>3000]}\end{array}$ & 0,916 & 0,26 \\
\hline $\begin{array}{l}\text { Sólidos Totais, } \\
\left(\mathrm{ST}, \mathrm{mgL}^{-1}\right)\end{array}$ & $\begin{array}{c}Q_{S T}=79-0,167284 \times S T+E X P\left[(R T)^{0,228}\right] \\
Q_{S T}=27,7\end{array}$ & $\begin{array}{c}{[0 \leq \mathrm{ST} \leq 1630]} \\
{[\mathrm{ST}>1630]}\end{array}$ & 0,990 & 0,22 \\
\hline $\begin{array}{c}\text { Dureza, } \\
\left(\text { DUR, } \mathrm{mgL}^{-1}\right)\end{array}$ & $\begin{array}{c}Q_{\text {DUR }}=100 \\
Q_{\text {DUR }}=101,1 \times \operatorname{EXP}(-0,00212 \times \text { DUR })\end{array}$ & $\begin{array}{l}{[\mathrm{DUR}<5,4]} \\
{[\mathrm{DUR} \geq 5,4]}\end{array}$ & 0,949 & 0,16 \\
\hline $\begin{array}{l}\text { Fluoreto, } \\
\left(\mathrm{F}, \mathrm{mgL}^{-1}\right)\end{array}$ & $\begin{array}{c}Q_{F}=80+21 \times F-(F)^{11,6263} \\
Q_{F}=0,0\end{array}$ & $\begin{array}{c}{[0 \leq \mathrm{F} \leq 1,5]} \\
{[\mathrm{F}>1,5]}\end{array}$ & 0,924 & 0,16 \\
\hline $\begin{array}{c}\text { Nitrato, } \\
\left(\mathrm{N}-\mathrm{NO}_{3}, \mathrm{mgL}^{-1}\right)\end{array}$ & $Q_{N}=100 \times \operatorname{EXP}(-0,0994 \times N)$ & {$[N \geq 0,0]$} & 0,993 & 0,15 \\
\hline \multicolumn{4}{|c|}{ Soma total dos pesos } & 1,00 \\
\hline
\end{tabular}

\section{Determinação dos pesos}

Os pesos $\left(\mathrm{w}_{\mathrm{i}}\right)$ que ponderam a influência de cada parâmetro na formulação do IQNAS foram escolhidos, inicialmente, com base na experiência de especialistas em hidrogeologia do Estado da Bahia. Em seguida, os valores propostos para os pesos $\left(\mathrm{w}_{\mathrm{i}}\right)$ foram testados sucessivamente no cálculo do IQNAS (Equação 01), utilizando-se as funções matemáticas para os parâmetros apresentadas na Tabela 1 . Os resultados obtidos foram submetidos à sucessivos refinamentos através de reuniões com os especialistas. Os valores finais encontrados para os pesos $\left(\mathrm{w}_{\mathrm{i}}\right)$ estão apresentados na Tabela 1.

\section{Intervalos de validade das funções matemáticas}

Com relação aos intervalos de validade das funções matemáticas apresentadas na Tabela 1, tem-se, por exemplo: Para os parâmetros cloreto e dureza, quando os valores de concentração são menores que 4,86 e $5,4 \mathrm{mgL}^{-1}$, respectivamente, o cálculo da qualidade resulta em valores maiores que 100, portanto, é preciso impor o valor máximo de qualidade 100. Para valores de cloreto > $3000 \mathrm{mgL}^{-1}$; sólidos totais > $1630 \mathrm{mgL}^{-}$ ${ }^{1}$; e fluoreto > $1,5 \mathrm{mgL}^{-1}$; como mostrado na Tabela 1, foi necessário tomar o menor valor de qualidade calculado, pois, acima destas concentrações, a função matemática passa a gerar valores inconsistentes.

\section{Cálculo e validação do IQNAS}

Foi realizada a análise de consistência dos dados hidroquímicos das águas subterrâneas de 14.000 poços cadastrados no banco de dados da Companhia de Engenharia Rural da Bahia CERB. Foram descartadas as análises incompletas ou oriundas de poços sem dados de coordenadas ou fora da zona de domínios hidrogeológicos específicos (cárstico, cristalino, metassedimentar e sedimentar). Após a análise de consistência, restaram 1.899 poços, os quais preencheram os seguintes requisitos: i) pertencem a um único domínio hidrogeológico; ii) possuem coordenadas geográficas; iii) apresentam todos os dados de análises químicas necessários à elaboração do índice.

Para o teste de validação, foram calculados os valores de IQNAS para amostras de todos os aqüíferos, investigando-se a coerência dos resultados, em comparação com a qualidade da água dada pela análise química. Enquanto os resultados não foram satisfatórios, o procedimento foi repetido, alterando-se a distribuição dos pesos, até que os valores calculados para o IQNAS ficaram compatíveis com a qualidade das águas. A Tabela 2 apresenta uma amostra do conjunto das análises químicas constantes no Banco de Dados da CERB; bem como os dados calculados para o IQNAS. 
Tabela 2 - Dados de Análises Químicas e Índice de Qualidade Natural das Águas Subterrâneas (IQNAS) do Domínio da Bacia Sedimentar do Recôncavo (Camaçari e São Sebastião do Passé) e do Calcário da Região de Irecê (Iraquara e Souto Soares), Estado da Bahia.

\begin{tabular}{|c|c|c|c|c|c|c|c|c|c|c|c|c|c|c|c|}
\hline \multirow{2}{*}{ Municípios } & \multirow{2}{*}{ № CERB } & \multirow{2}{*}{$\begin{array}{l}\text { Cloreto } \\
\mathrm{mgL}^{-1}\end{array}$} & \multirow{2}{*}{$\mathrm{pH}$} & \multirow{2}{*}{$\begin{array}{c}\text { Resíduos } \\
\text { Totais } \\
\mathrm{mgL}^{-1} \\
\end{array}$} & \multirow{2}{*}{$\begin{array}{l}\text { Dureza } \\
\mathrm{mgL}^{-1}\end{array}$} & \multirow{2}{*}{$\begin{array}{l}\text { Fluoreto } \\
\mathrm{mgL}^{-1}\end{array}$} & \multirow{2}{*}{$\begin{array}{l}\text { Nitrato } \\
\mathrm{mg} / \mathrm{L}\end{array}$} & \multicolumn{6}{|c|}{ Notas ou Qualidade das Variáveis* } & \multirow{2}{*}{$\begin{array}{l}\text { Valores } \\
\text { IQNAS }\end{array}$} & \multirow{2}{*}{$\begin{array}{c}\text { Tipo de } \\
\text { Aqüífero }\end{array}$} \\
\hline & & & & & & & & $\mathrm{Q}_{\mathrm{Cl}}$ & $\mathrm{Q}_{\mathrm{pH}}$ & $Q_{S T}$ & QDUR & $Q_{F}$ & $Q_{N}$ & & \\
\hline \multirow{4}{*}{$\begin{array}{c}\text { Dias D’Avila } \\
\text { (Águas } \\
\text { Minerais) }\end{array}$} & Fresca & 8,97 & 6,90 & 40,00 & 11,10 & 0,17 & 0,22 & 87,92 & 82,62 & 82,47 & 98,87 & 83,57 & 97,84 & 88,76 & Sedimentar \\
\hline & Indaiá & 8,97 & 5,07 & 44,70 & 8,07 & 0,11 & 0,22 & 87,92 & 44,61 & 82,31 & 99,47 & 82,31 & 97,84 & 85,90 & Sedimentar \\
\hline & Indaiá & 7,97 & 4,87 & 36,00 & 4,03 & 0,13 & 0,23 & 90,16 & 41,16 & 82,60 & 100,00 & 82,73 & 97,74 & 86,32 & Sedimentar \\
\hline & Indaiá & 8,97 & 5,20 & 38,50 & 4,00 & 0,10 & 0,24 & 87,92 & 46,93 & 82,52 & 100,00 & 82,10 & 97,64 & 86,18 & Sedimentar \\
\hline \multirow{2}{*}{$\begin{array}{l}\text { Alagoinhas } \\
\text { (Agguas } \\
\text { Minerais) } \\
\end{array}$} & Schincariol & 11,00 & 7,10 & 75,00 & 13,00 & 0,28 & 0,10 & 84,16 & 87,48 & 80,98 & 98,49 & 85,88 & 99,01 & 88,14 & Sedimentar \\
\hline & Schincariol & 11,00 & 6,87 & 86,00 & 12,10 & 0,35 & 0,0 & 84,16 & 81,91 & 80,43 & 98,67 & 87,35 & 100,00 & 88,12 & Sedimentar \\
\hline \multirow{5}{*}{ Camaçari } & $1-1258$ & 10,5 & 8,20 & 72,0 & 52,0 & 0,06 & 0,0 & 85,00 & 68,20 & 81,13 & 91,07 & 81,26 & 100,00 & 85,59 & Sedimentar \\
\hline & $1-230$ & 9,50 & 6,90 & 74,8 & 6,50 & 0,0 & 0,0 & 86,85 & 82,62 & 80,99 & 99,79 & 80,00 & 100,00 & 87,93 & Sedimentar \\
\hline & $1-314$ & 11,5 & 6,05 & 36,2 & 13,0 & 0,0 & 0,0 & 83,35 & 63,52 & 82,59 & 98,49 & 80,00 & 100,00 & 86,05 & Sedimentar \\
\hline & $1-3013$ & 13,6 & 6,80 & 72,0 & 26 & 0,0 & 0,0 & 80,37 & 80,24 & 81,13 & 95,95 & 80,00 & 100,00 & 85,54 & Sedimentar \\
\hline & $1-1287$ & 6,5 & 7,00 & 34 & 5,0 & 0,06 & 0,0 & 94,12 & 85,03 & 82,65 & 100,00 & 81,26 & 100,00 & 90,58 & Sedimentar \\
\hline \multirow{5}{*}{$\begin{array}{l}\text { São } \\
\text { Sebastião do } \\
\text { Passé }\end{array}$} & $1-4104$ & 33,3 & 7,36 & 112 & 80,3 & 0,80 & 0,0 & 65,61 & 94,63 & 79,04 & 86,03 & 96,73 & 100,00 & 82,41 & Sedimentar \\
\hline & $1-4098$ & 101,85 & 7,20 & 280,0 & 160 & 0,48 & 0,0 & 49,25 & 89,96 & 69,26 & 73,30 & 90,08 & 100,00 & 71,42 & Sedimentar \\
\hline & $1-378$ & 20,0 & 6,50 & 160,0 & 26,0 & 0,02 & 0,0 & 73,79 & 73,32 & 76,30 & 95,95 & 80,42 & 100,00 & 82,24 & Sedimentar \\
\hline & $1-1359$ & 356,3 & 7,00 & 774 & 183 & 0,12 & 0,0 & 32,21 & 85,03 & 44,77 & 69,98 & 82,52 & 100,00 & 56,71 & Sedimentar \\
\hline & $1-2462$ & 49,3 & 8,60 & 240 & 96,0 & 0,49 & 0,0 & 59,66 & 58,64 & 71,60 & 83,36 & 90,29 & 100,00 & $\mathbf{7 5 , 5 8}$ & Sedimentar \\
\hline \multirow{5}{*}{ Iraquara } & 1_6490 & 374 & 7,11 & 1910 & 889 & 1,18 & 57,7 & 31,55 & 87,73 & 27,70 & 16,93 & 97,93 & 0,32 & 17,61 & Calcário \\
\hline & 3_3128 & 56,6 & 7,62 & 2728 & 2111 & 2,65 & 0,03 & 57,62 & 86,36 & 27,70 & 1,45 & 0,00 & 99,70 & $\mathbf{0 , 0 0}$ & Calcário \\
\hline & 1_3404 & 17,6 & 7,80 & 494 & 315 & 0,57 & 0,0 & 75,93 & 79,55 & 57,50 & 53,68 & 91,97 & 100,00 & 72,78 & Calcário \\
\hline & 2_1147 & 28,7 & 8,18 & 404 & 254 & 0,20 & 0,01 & 67,94 & 68,72 & 62,26 & 60,68 & 84,20 & 99,90 & 71,81 & Calcário \\
\hline & 2_697 & 44,8 & 6,60 & 86,0 & 18,3 & 0,14 & 0,00 & 61,09 & 75,59 & 80,43 & 97,45 & 82,94 & 100,00 & 79,92 & Calcário \\
\hline \multirow{5}{*}{ Souto Soares } & 1_6770 & 806 & 7,95 & 2940 & 1442 & 2,69 & 0,00 & 20,89 & 75,06 & 27,70 & 5,57 & 0,00 & 100,00 & 0,00 & Calcário \\
\hline & 3_3663 & 185 & 8,14 & 730 & 479 & 0,50 & 1,85 & 41,07 & 69,78 & 46,55 & 38,60 & 90,50 & 83,20 & 54,15 & Calcário \\
\hline & 1_5642 & 83,0 & 8,45 & 752 & 401 & 0,86 & 3,38 & 52,12 & 62,04 & 45,65 & 45,15 & 97,89 & 71,46 & 57,88 & Calcário \\
\hline & 1_4917 & 269 & 8,20 & 1796 & 987 & 1,26 & 1,70 & 36,01 & 68,20 & 27,70 & 13,90 & 91,77 & 84,45 & \multirow{2}{*}{$\begin{array}{l}39,78 \\
79,92 \\
\end{array}$} & Calcário \\
\hline & 1_5530 & 32,6 & 5,85 & 94,0 & 18,9 & 0,00 & 0,05 & 65,94 & 59,39 & 80,01 & 97,33 & 80,00 & 99,50 & & Quartzito \\
\hline
\end{tabular}


Construção dos mapas de qualidade das águas subterrâneas

Os mapas semafóricos construídos com o Índice de Qualidade das Águas Subterrâneas foram obtidos espacializando-se os valores do IQNAS nos vários domínios hidrogeológicos do Estado da Bahia. Nas áreas onde as observações não estavam disponíveis, utilizou-se a krigagem (KRIGE, 1951; DAVIS, 1973), método estatístico disponível no programa Arcgis, para fazer as interpolações.

Para que a interpolação de uma variável seja válida, utilizando-se o método de krigagem, é necessário que esta se comporte como uma variável regionalizada, ou seja, esteja distribuída geograficamente; seja de ocorrência natural; e tenha características intermediárias entre determinísticas e aleatórias (DAVIS, 1973). Diferentemente das variáveis aleatórias, variáveis regionalizadas têm continuidade de ponto a ponto, mas suas variações são tão complexas que não podem ser representadas por funções determinísticas. O grau de continuidade espacial dessas variáveis regionalizadas pode ser estimado pela função estatística, semivariância $(\gamma)$. A semivariância expressa a taxa de alteração da variável regionalizada como função da distância, separando dois locais, e, ao longo de uma direção especificada. $\mathrm{O}$ gráfico dos valores da semivariância $(\gamma)$ para diferentes distâncias (h) é o semivariograma. Se a variável é regionalizada, para pontos muito próximos a semivariância tende a ser pequena; ao crescer as distâncias, as variáveis são cada vez menos relacionadas e as diferenças ficam maiores. Para grandes valores de $h$, a semivariância deixa de crescer e o semivariograma fica estacionário apresentando uma forma em platô. Portanto, para uma adequada previsão dos valores não medidos de uma variável regionalizada, a condição necessária é que o semivariograma seja estacionário.

Na figura 4 estão apresentados gráficos dos semivariogramas para três parâmetros físicoquímicos da água subterrânea do Estado da Bahia (cloreto, dureza e nitrato), extraídos de Negrão (2008); e o semivariograma para os valores de IQNAS.

O semivariograma para valores de IQNAS dos 1899 poços, nos quatro domínios hidrogeológicos, mostra estacionaridade, com alguma oscilação, em comparação ao semivariograma dos parâmetros químicos, cloreto e dureza, mostrados na figura 4. $\mathrm{O}$ semivariograma do nitrato apresenta o efeito pepita, ou seja, a variável não é regionalizada; efeito que pode ter influenciado para a irregularidade no semivariograma do IQNAS. A despeito das oscilações no semivariograma do IQNAS, o fato de ter apresentado estacionaridade justificou o uso da krigagem para a interpolação destes valores. Os mapas gerados com os valores de IQNAS, através do procedimento de krigagem, representam adequadamente o comportamento espacial da qualidade das águas subterrâneas do Estado da Bahia.

As áreas de igual valor de IQNAS, geradas pelo Arcgis, são associadas aos intervalos de qualidade definidos da seguinte forma: qualidade ótima (80,01 a 100,00); boa (52,01 a 80,00); aceitável (37,01 a 52,00) e qualidade imprópria (0 a 37,00).

\section{RESULTADOS E DISCUSSÃO}

O mapa da figura 5 apresenta a espacialização do IQNAS para os diversos domínios hidrogeológicos do Estado da Bahia.

Verifica-se que o domínio das bacias sedimentares e coberturas apresentam as melhores notas, seguidas pelo metassedimentar, cárstico e, por fim, pelo cristalino semi-árido. Esta representação mostra-se bastante satisfatória, retratando com fidelidade a qualidade dessas águas.

Para examinar em detalhe a distribuição dos valores do IQNAS, em cada um dos domínios aquífferos do Estado, foram elaborados os mapas semafóricos figuras (6 a 10 seguintes), para cada aquiífero em separado.

O mapa da figura 6 para o Domínio das Coberturas Detríticas, mostra águas de melhor qualidade localizadas nas regiões de pluviometria elevada; ao leste, nas bacias sedimentares; e à oeste, nas coberturas profundas às margens do Rio São Francisco. 


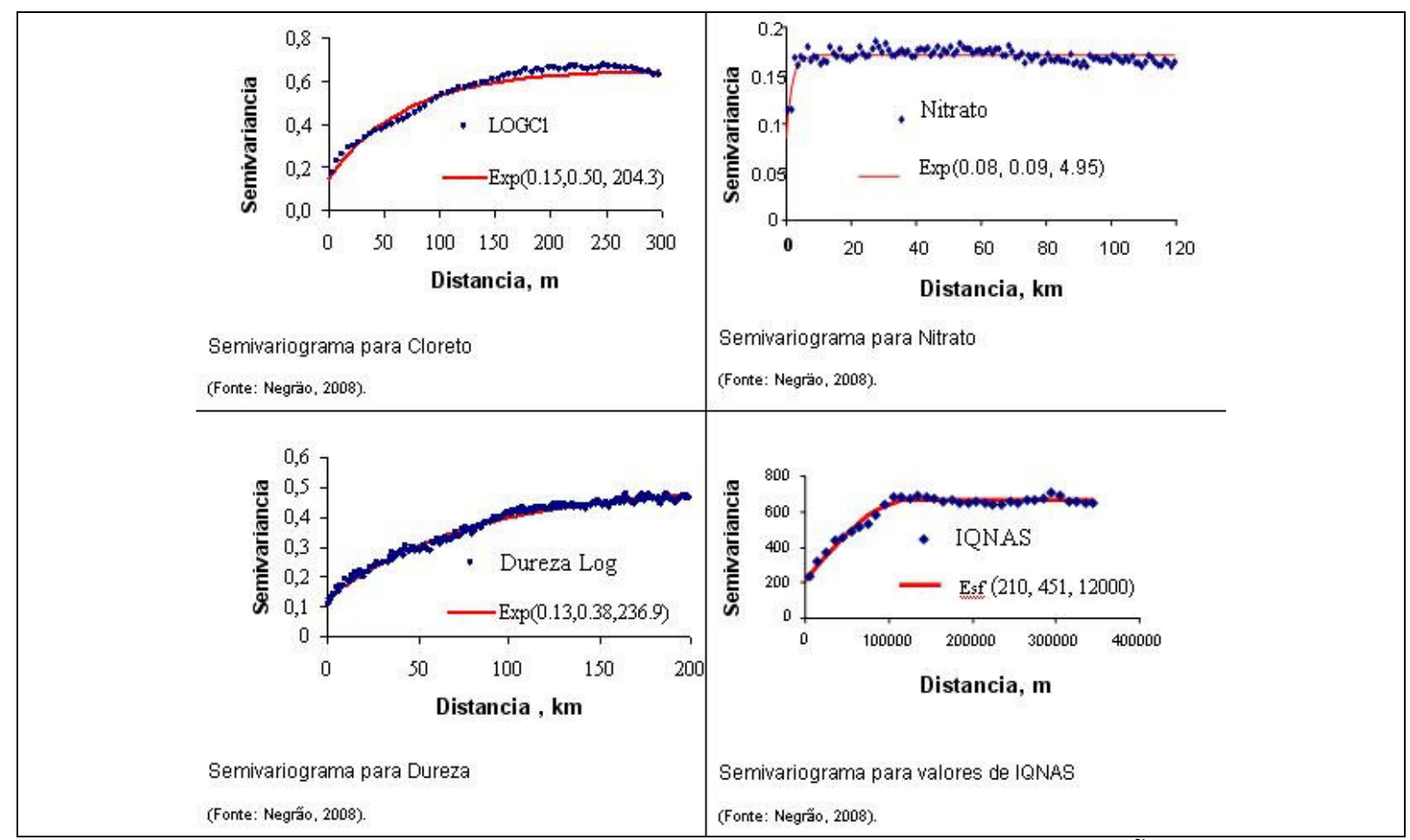

Figura 4 - Semivariogramas para os parâmetros Cloreto, Dureza e Nitrato (Fonte: NEGRÃO, 2008); e para os valores de IQNAS.

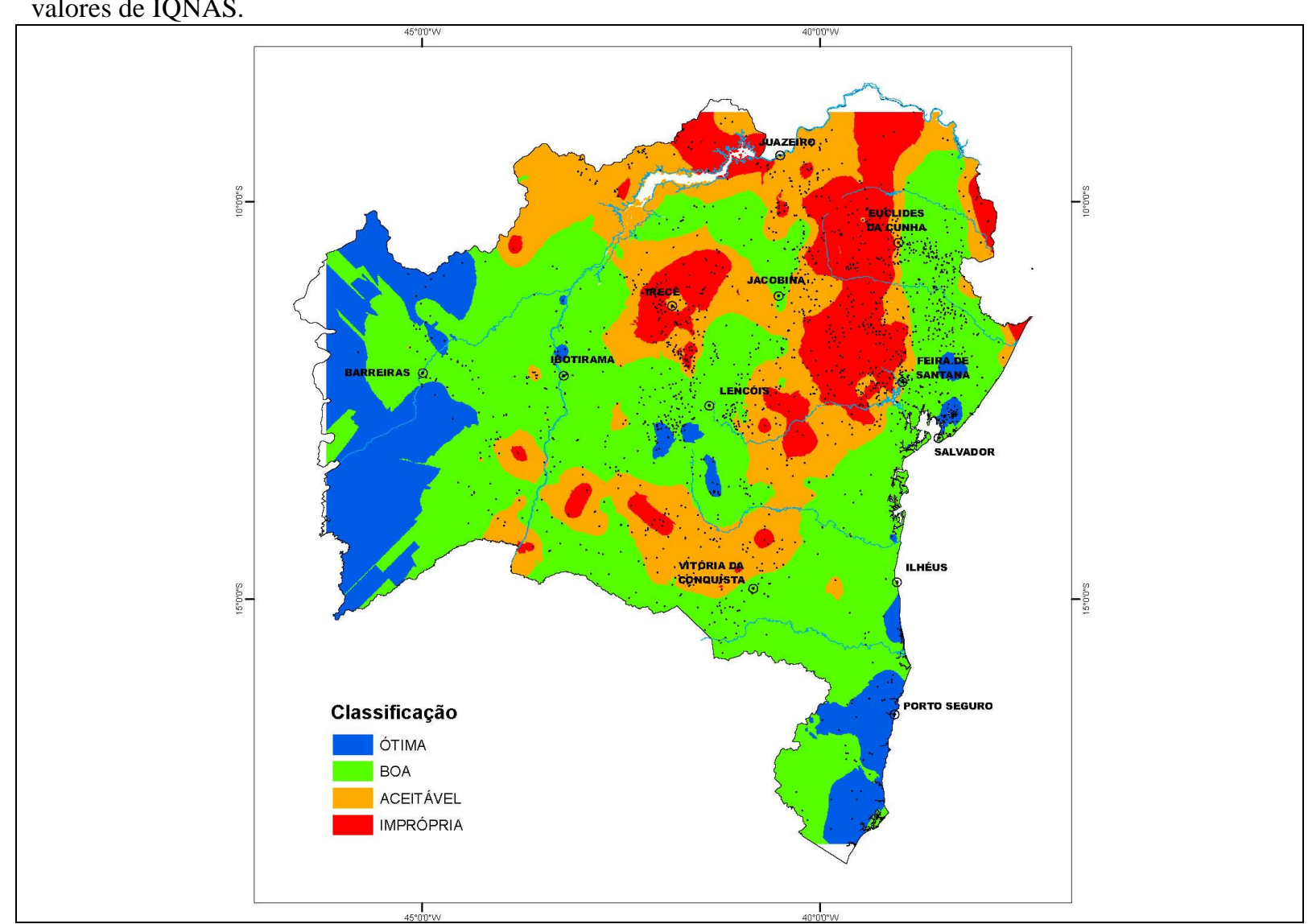

Figura 5 - Mapa semafórico do IQNAS para o estado da Bahia. 


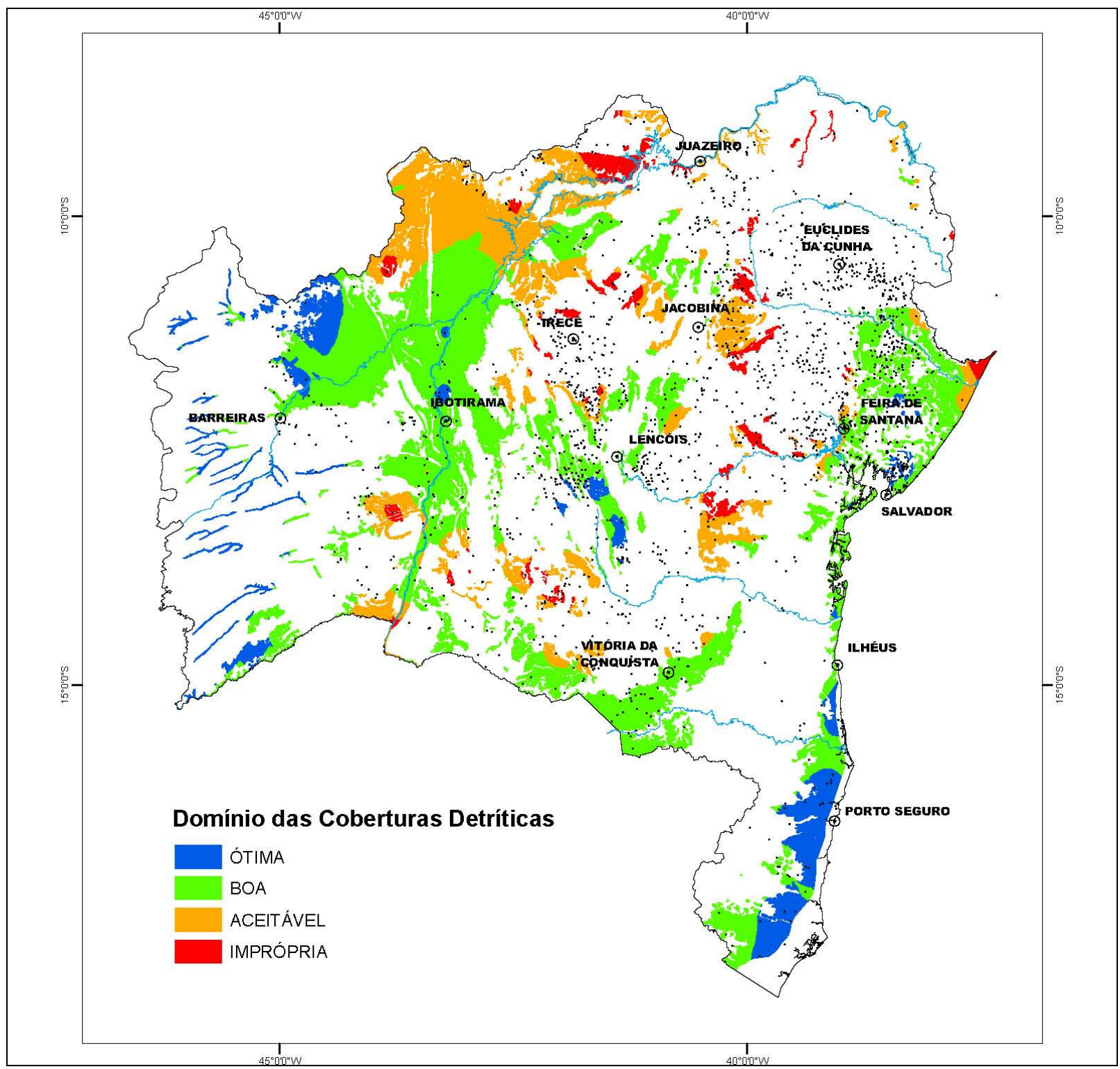

Figura 6 - Mapa semafórico do IQNAS para o domínio aquíífero das coberturas detríticas.

O mapa da figura 7 corresponde ao Domínio das Bacias Sedimentares que se compõem predominantemente de terrenos arenosos com grandes volumes de águas doces.

Verifica-se que as águas são de qualidade predominante ótima a boa nas regiões de alta pluviosidade; a leste, nos aquífferos da Bacia do Recôncavo, Tucano, Sul e Extremo Sul e, à oeste, no aqüífero Urucuia.

O mapa da figura 8 corresponde ao Domínio Metassedimentar que possui características semelhantes às rochas do Domínio Cristalino (fissural).

O mapa mostra que a qualidade da água tem predominância boa à ótima devido à composição mineralógica desse domínio ser predominantemente quartizítica, e, por estar localizado em zonas de maior pluviosidade, à exemplo da região da Chapada Diamantina.

O mapa da figura 9 corresponde ao Domínio Calcário, formado por rochas carbonáticas e margas. O mapa mostra predominância da qualidade aceitável a imprópria, pois as águas são carregadas de carbonato de cálcio e magnésio. Quanto à qualidade imprópria das águas do Domínio Cárstico na região de Irecê, tal fato se deve à intensa aplicação de fertilizantes nitrogenados na agricultura irrigada; bem como pelo volume dos efluentes domésticos lançados in natura no solo. Tais fatos vêm causando o aumento de nitratos nas águas subterrâneas já há algumas décadas (NEGRÃO, 1987). 


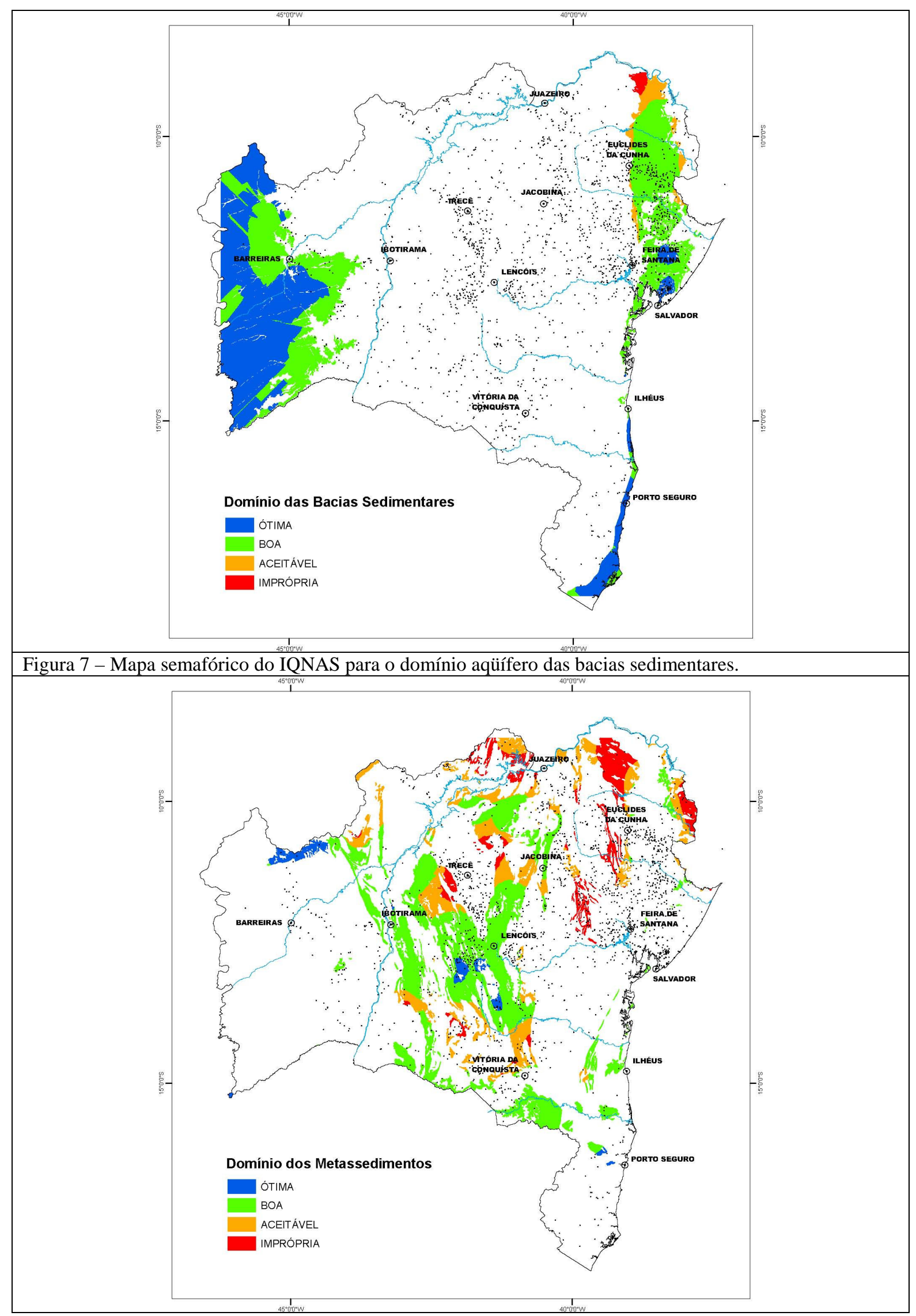

Figura 8 - Mapa semafórico do IQNAS para o domínio aqüífero metassedimentar. 


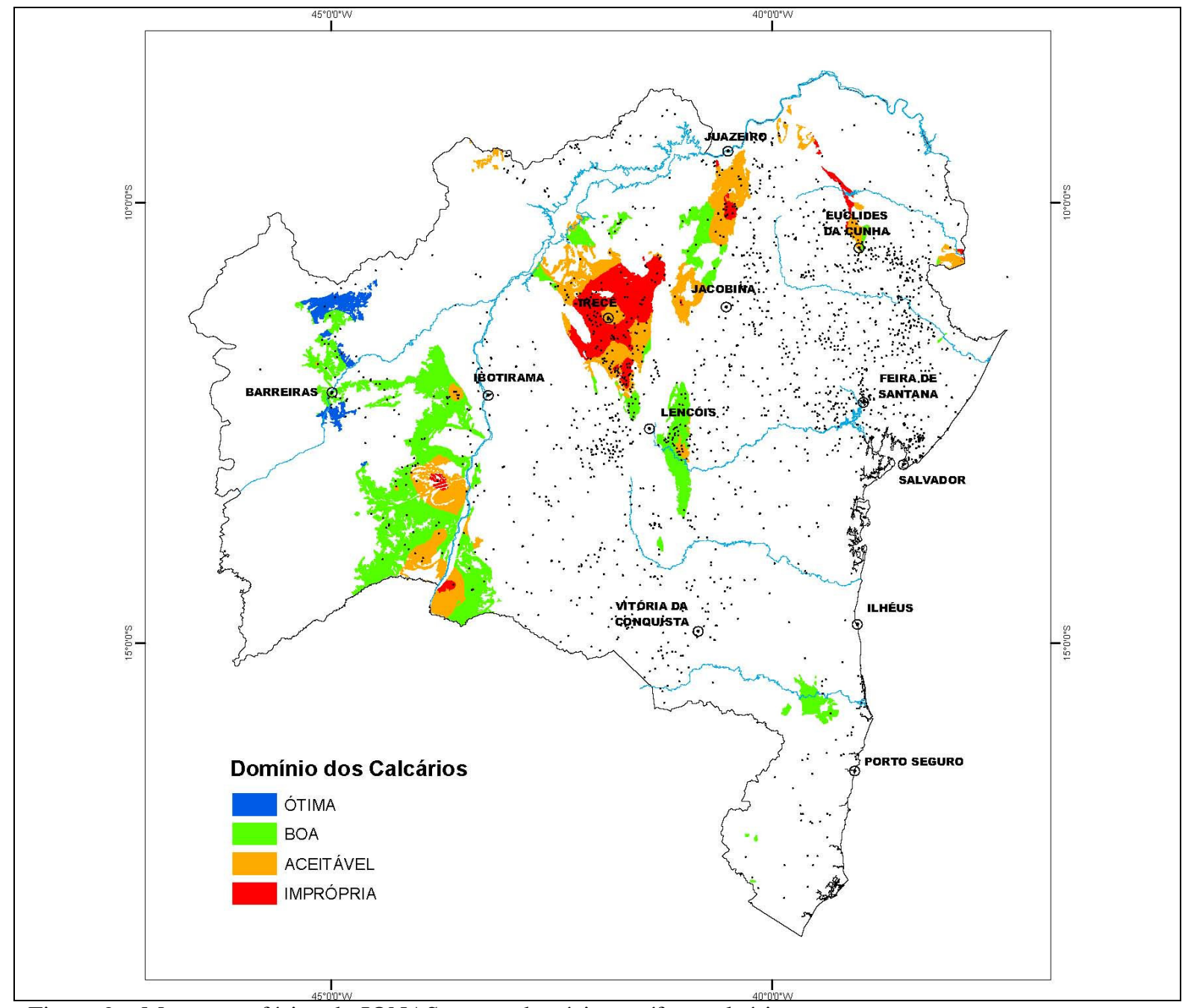

Figura 9 - Mapa semafórico do IQNAS para o domínio aquiífero calcário.

No entanto, o mapa também mostra águas classificadas como de qualidade boa e ótima as quais estão concentradas nas regiões de pluviosidade mais alta: Chapada Diamantina e região do oeste do São Francisco.

O mapa da figura 10 corresponde ao Domínio do Embasamento Cristalino, o qual acumula água nas fendas ou fissuras resultantes do fraturamento.

Nos aqüíferos cristalinos das regiões semiáridas, fatores ligados ao clima e a variedade de composição das rochas constituintes, são responsáveis pela predominância de notas de qualidade aceitável à imprópria. Nesse domínio predominam rochas ricas em minerais ferromagnesianos; baixas recargas; e altas taxas de evaporação, fatores favoráveis à concentrando de sais na água subterrânea. Por estas razões menos de um quarto de suas águas apresentam notas na qualidade boa à ótima.

Por outro lado, quando os aqüíferos cristalinos ocorrem em regiões de maior índice pluviométrico, melhora a qualidade da água devido à recarga mais frequiente, renovando as águas presentes nas fendas.

O mapa da figura 10 mostra duas regiões, com comportamentos distintos. Ao sul, com precipitações acima de 800 milímetros ao ano, as águas são de melhor qualidade; e ao norte com precipitações abaixo deste valor, as águas são de qualidade aceitável a imprópria. Ou seja, a baixa taxa de recarga dos aqüíferos implica na maior concentração de sais na água, tornando-as, muitas vezes, extremamente salinizadas. 


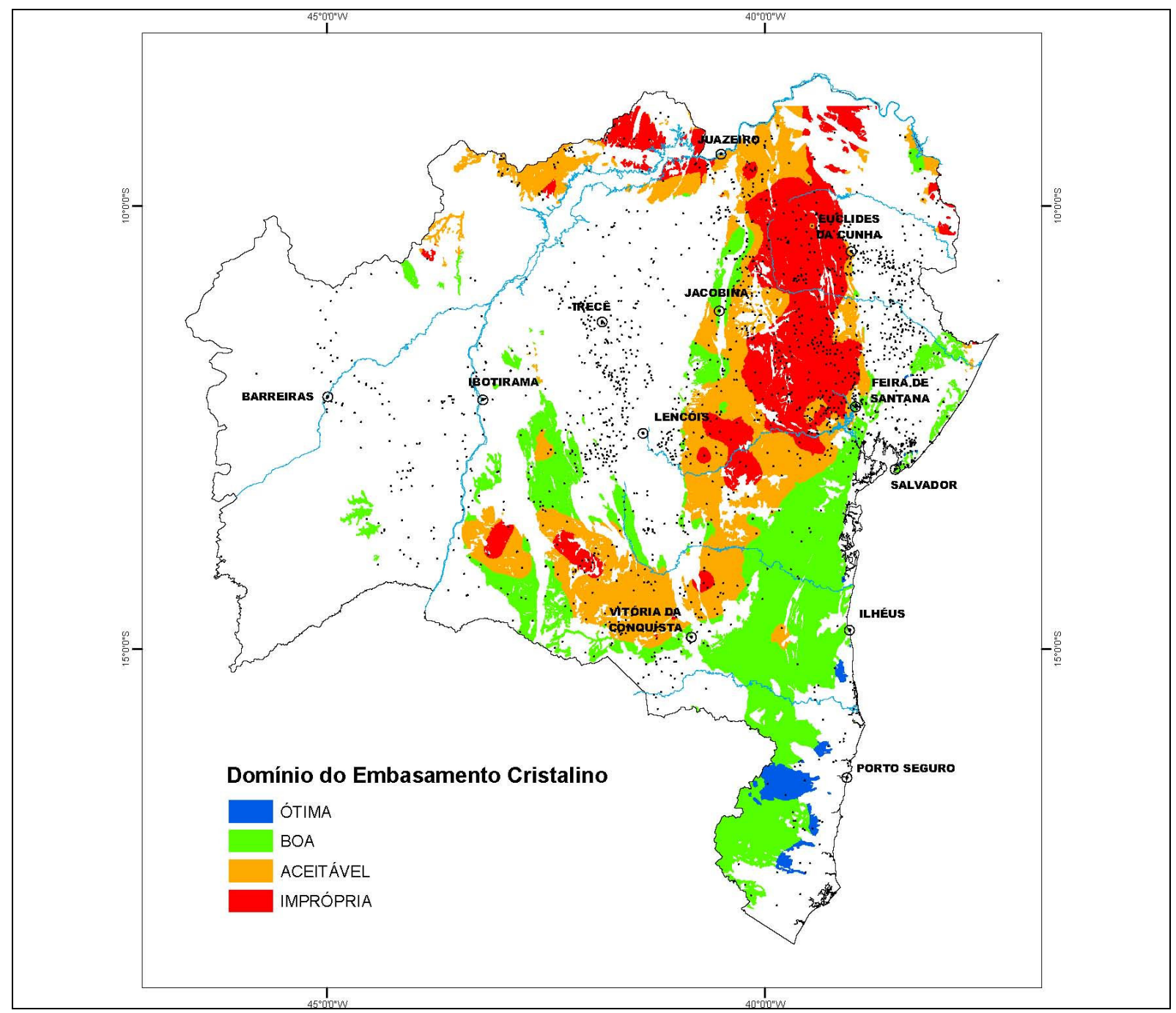

Figura 10 - Mapa semafórico do IQNAS para o domínio aqüífero embasamento cristalino.

\section{CONCLUSÕES}

Os valores do IQNAS encontrados quantificaram e qualificaram adequadamente as águas subterrâneas dos principais Domínios Hidrogeológicos ou Aqüíferos do Estado da Bahia, confirmando positivamente a metodologia adotada.
A praticidade do método, juntamente com a facilidade de compreensão dos resultados fornecidos pelo mesmo, habilita o índice criado a ser adotado por outros pesquisadores, no sentido de desenvolverem possíveis melhorias e agregarem mais conhecimento na geração de indicadores de qualidade das águas subterrâneas. 


\section{REFERÊNCIAS}

BAHIA. Secretaria de Infra Estrutura - SEI / Superintendência de Recursos Hídricos, Plano Estadual de Recursos Hídricos. Consórcio MAGNABRL, Salvador, Bahia. CD-ROM, Tomo 1 e 2. 2003.

COLLINS, W.D. Graphic Representation of Analyses. Indus. and Eng. Chemistry, V. 15, p.394, 1923.

DAVIS, J. C. Statistics and data analysis in geology. New York, John Wiley, 550p. 1973.

FOURNIER, I.L. SEQ-Eaux Souterraines - Système d'évaluation de la qualité Revue de L’Agence de leau, n.81, p.19, Fever.2001, disponível em http://sandre.eaufrance.fr/IMG/pdf/SEQ_ Esout.pdf Acesso 10/05/2006.

GASTALDINI, M.C.C. SOUZA, M.D.S, Diagnóstico do Reservatório do Vacacaí-Mirim através de Índices de Qualidade de Água. Anais do $1^{\circ}$ Seminário sobre Qualidade de Águas Continentais no Mercosul, Porto Alegre. 1994.

GUERRA, A.M. Processos de Carstificação e Hidrogeologia do Grupo Bambuí na Região de Irecê Bahia. Tese de Doutorado, Instituto de Geociências, USP, São Paulo, 1986.

GUERRA, A.M.; NEGRÃO, F.I. Domínios Hidrogeológicos do Estado da Bahia. Anais do IX Congresso Brasileiro de Águas Subterrâneas, Salvador, Bahia. 1996.

KRIGE, D.G. A statistical approach to some basic mine evaluation problems on the Witwatersrand. J. Chem. Metall. Min. Soc. S. Afri., Johannesburg, 52: 119-139, 1951.

LEITE, F.; FONSECA, O. Aplicação de índices de qualidade das águas na Lagoa Caconde, Osório, RS. Anais do Seminário de Qualidade das Águas Continentais no Mercosul, Organizador: David M. Marques - ABRH. 1994.

NEGRÃO, F.I. Caracterização Hidrogeoquímica e Vulnerabilidade do Sistema Hidrogeológico Cárstico da Região de Irecê-Ba. Dissertação de Mestrado, Instituto de Geociências da Universidade de São Paulo - USP, 1987.

NEGRÃO F.I. Hidrogeologia do Estado da Bahia: qualidade, potencialidade, disponibilidade, vulnerabilidade e grau de poluição. Tese de Doutorado, Instituto Universitario de Xeoloxía Isidro Parga Pondal da Universidade da Coruña, Espanha, 2008.

NSF - NATIONAL SANITATION FOUNDATION Water Quality Index, disponível em http://www.nsf.org/consumer/eauth_day/wqi.asp

Acesso em: 28 Agosto 2004.

OLIVEIRA, I.B., NEGRÃO, F.I.; ROCHA, T.S. Determinação do Índice de Qualidade da Água Subterrânea - IQAS, com base nos dados de Poços Tubulares do Estado da Bahia. (Área Piloto: Recôncavo). Anais do III Congresso Nacional de Meio Ambiente; Salvador - Ba., 11-17 de Outubro de 2004a.

OLIVEIRA, I.B.,NEGRÃO, F.I.; ROCHA, T.S. Determinação do Índice de Qualidade da Água
Subterrânea - IQAS, com base nos dados de Poços Tubulares do Estado da Bahia (Áreas Piloto: Recôncavo e Região de Irecê). Anais do XIII Congresso Brasileiro de Águas Subterrâneas; CuiabáMT. 19-22 de Outubro de 2004b.

OLIVEIRA I.B., NEGRÃO, F.I., SILVA, A.G.L.S, ROCHA, T.S.; ALMEIDA, R.A.S. Construção do Índice de Qualidade Natural das Águas Subterrâneas IQNAS. Anais do XI Fórum de Tecnologia Limpa, Escola Politécnica da UFBA. Rede de Tecnologias Limpas. Salvador Ba. 28 a 30 de Setembro de 2005.

OLIVEIRA I.B., NEGRÃO, F.I., SILVA, A.G.L.S. Aplicação do Índice de Qualidade das Águas Subterrâneas - IQNAS, Para os Domínios Hidrogeológicos do Estado da Bahia. Anais do XIV Congresso Brasileiro de Águas Subterrâneas. Curitiba/PR, 7-10 Novembro de 2006.

PORTO, R.L.L. Estabelecimento de parâmetros de controle da poluição. In: PORTO, R. L. L., BRANDO, S.M., CLEARY, R.W. et al., Hidrologia ambiental. São Paulo: Associação Brasileira de Recursos Hídricos, ABRH, 1991.

PIPER, A.M. A graphic procedure in the geochemical interpretation of water analyses. Am. Geophysics Union Trans., V 25, 914 - 923. 1944.

PNMA, Índice e indicadores de qualidade da água Revisão da Literatura. Ano 2006. Disponível em http://www.cprh.pe.gov.br/downloads/indice-aguavolume1.pdf. Acesso em 03.04.2008.

SCHOELLER, H., Geochemic des eaux souterraines. Revue de L'Institute Fançais du Petrole, V 10, 230244. 1955.

SILVA, A.G.L., OLIVEIRA I.B., e NEGRÃO, F.I. Determinação do Índice de Qualidade Natural das Águas Subterrâneas IQNAS, com Base nos Dados de Poços Tubulares do Estado da Bahia. Livro de Resumo do XXIV Seminário Estudantil de Pesquisa SEMEP, UFBa. Salvador, Ba., 9-12 de Novembro de 2005.

STIFF, H.A. Jr., The interpretation of chemical water analysis by means of patterns. Journal Petroleum Technology, V. 3, No. 10, 15-17. 1951.

\section{AGRADECIMENTOS}

Companhia de Engenharia Rural da Bahia (CERB) pela sessão dos dados de poços tubulares; à Fundação de Auxílio à Pesquisa do Estado da Bahia (FAPESB), pelo apoio ao hidrogeólogo, pesquisador deste projeto, e à bolsista de Iniciação Científica; e ao CNPq, pela aprovação do Projeto ACQUAINDEX. Aos alunos de Iniciação Científica, Patrícia Silva Souza e Rogério Baqueiro Silva pela elaboração do semivariograma do IQNAS. 
